\title{
THE SINO-AURICULAR NODE: A HISTORICAL NOTE
}

\author{
CONTRIBUTED BY
}

\section{ARTHUR KEITH}

The Editors of the British Heart Journal have reason to pride themselves on the publication of this article in which Professor Francis Davies sums up the results of a long and careful examination of the conducting muscular system of the vertebrate heart. He has made discoveries of outstanding importance - especially the existence in the bird's heart of a system more highly evolved than even that of the mammalian heart (which Dr. Ivy McKenzie and I had searched for and missed); no less outstanding in importance is his success in following the ultimate branches of the A-V bundle to their termination in the ventricular musculature.

While reading the proof sheets of Professor Davies's article, there came back to me the memory of a letter I received from the late Sir James MacKenzie (then in Burnley) informing me of Tawara's discovery of the A-V conducting bundle in the mammalian heart. The letter came late in 1905 or early in 1906. I had then been at work on the anatomy of the heart for five or six years, * and thought I knew all that was to be found in that organ. Indeed, I was so sceptical of the existence of the bundle that I had drafted a letter to the Lancet denying its existence but, fortunately for me, made one more search before committing myself, and found in the human heart all as Tawara had described it, and then wondered how I had missed a structure that was so evidentwhen once seen. So the letter was amended and dispatched (Lancet, 1906, 1, 623). I took the lesson as a warning and yet repeated the mistake a few years later when searching for an A-V system in the bird's heart. Probably my microscopic technique was at fault; I have always envied men who were masters of microscopic technique-almost as much as I envied my friends who could hold free converse in foreign languages.

My partnership with MacKenzie of Burnley must have begun about 1904; he sent me hearts of his more famous cases to see if I could find a pathological basis for their irregularities. I dissected and drew them, cut sections of all parts, but after many months of close observation got no definite correlation between the type of arrhythmia and a pathological lesion, so great was the variation in microscopic appearance as I went from heart to heart. But one thing I did find that afterwards proved to be of significance. At the time

* Readers will find my work of that time buried in the Proceedings of the Anatomical Society (published in the Journal of Anatomy), from 1902 onwards. 
we were all impressed by the fact that in lower vertebrates the contraction wave of the heart was initiated in the sinus venosus. Hence in cutting MacKenzie's hearts I made my sections so as to expose the remnants of the sinus which are included in the right auricle. In all my sections which traversed the sulcus terminalis where the superior vena cava entered the right auricle (the sulcus marking the infolding of the sinus) I noted a localized density of tissue in which nerve fibres seem to terminate. So variable was this structure in its density and form in hearts that had manifested irregularities of rhythm and in others that were reputed to have been normal in action, that I passed it by as having no functional significance. This was before Tawara had made his discovery.

At that time my wife and I rented a farmhouse in Kent, where we spent vacations. We lived near the village of Bredgar, famous for its cherry orchards; a neighbouring village was Borden where lived the Flack family. We heard that Martin Flack, just down from Oxford, was looking for a hospital at which to continue his medical studies and lost no time in putting before him the attractions of the London Hospital, where I taught anatomy and Leonard Hill physiology. Martin joined us; indeed he became more Hill's pupil than mine. His was a most attractive personality, fair haired, clean skinned, bright-eyed, short and sturdy-my ideal of a Saxon youth; merry, ever ready for work or play; as true and lovable a man as I have met.*

In the long vacation of 1906, Flack and I turned my study at Bredgar into a laboratory-microtome, oven, microscopes; we had a vast store of human hearts and were trapping moles, rats, mice, and hedgehogs with the intention of verifying and extending Tawara's discoveries on their hearts. I remember well one very hot day, late in the summer of 1906, my wife and I going out on our bicycles leaving Martin running serial sections of a mole's heart. On returning he bade me look through a microscope at a strange structure he had found at the junction of the superior cava with the right auricle. The structure was muscular but quite different from the musculature round about. I remembered the body I had seen in the MacKenzie hearts; we set to work and found it at the same site in all the mammalian hearts at our disposal. In structure it resembled the node of Tawara; hence we inferred it to be the site at which the cardiac rhythm was normally initiated (J. Anat. (1907) 41, 173).

That is the beginning of our knowledge of the S-A node in the rough. Professor Davies has produced the finished article. Yet there are one or two points in his account that leave me unsatisfied. There is the relation of nodes to nerves which is left untouched. There is the secretory side of nodal function to be considered-or rather the excretory or secretory hormone formed at neuro-nodal junctions. Therein lies the central nervous control of the cardiac rhythm. After all, nerve cell and muscular cell have a common ancestry and there is still room to believe there may be cells which retain the common ancestral qualities of irritability and contractibility and that nodal cells do retain these original characters. I wish someone would again examine the sino-auricular

\footnotetext{
* In the 1914-18 war, Dr. Flack became scientific advisor to the Medical Department of the embryonic R.A.F. He died August 16, 1931, just when his great ability was meeting with a wide and deserved recognition.
} 
node of Ornithorychus; my sections are lost, but I believed I could trace in them a direct continuity of nerve fibre and nodal cellular element.

Professor Davies regards the muscular connecting system of the mammalian and avian heart as a new formation-one which appeared in the evolution of animals at the same time as a temperature regulating system. Such a sudden appearance would be an example of emergent evolution-a form of evolution I have the same antipathy to as I have for miraculous happenings of all kinds. They are made believable by blanks in our knowledge. We know enough to reject the idea that warm-blooded beasts appeared suddenly; there are still intermediates in this respect-the Monotremes. I agree that heart action and body temperature must have been coordinated in their evolution, but, although the detection of the coordinating mechanism in the evolving or developing animal body still eludes us, that in no wise shakes our confidence that it exists and will be discovered. And its foundation will be found not in something interpolated but in an emergence from something that has gone before. The A-V bundle may have developed as Professor Shaner has described and still be a modification of the auriculo-ventricular function of the cold-blooded heart. 